\title{
Relationship between Aflatoxin B1 Exposure and Etiology of Liver Disease in Saudi Arabian Patients
}

\author{
Randa M Farag ${ }^{1,}$; Dujana AlAyobi2; Khalid A Alsaleh ${ }^{3}$; Ehab A Serour ${ }^{4}$; Hye-Joo Kwon ${ }^{5}$ \\ Afaf EL-Ansary ${ }^{6}$
}

${ }^{*}$ Corresponding author, Assistant Prof of Virology and molecular microbiology, Health Science Research Central, Princes Nora University (PNU), Riyadh 12484, Kingdom Saudi Arabia (KSA); Randa792006@gmail.com; rmfarj@pnu.edu.sa; http://dx.doi.org/0000-0002-67050235

${ }^{2}$ Prof of Genetic, Biology department, Princes Nora University (PNU), Riyadh 12484, Kingdom Saudi Arabia (KSA); Prof.dujana@live.com

3 Prof of oncology and Hematology, college of Medicine, King Saud University (KSU), Riyadh 12372, Kingdom Saudi Arabia (KSA); Khaalsaleh.kaa@ksu.edu.sa,khalid_alsaleh@hotmail.com

${ }^{4}$ Prof of Biochemistry, King Abdu-Aziz city for science and technology (KACST), Riyadh 12371, Kingdom Saudi Arabia (KSA); eserour@kacst.edu.sa

${ }^{5}$ Assistant Prof of molecular biology, Biology department, Princes Nora University (PNU), Kingdom Saudi Arabia (KSA); hjkwon@pnu.edu.sa

${ }^{6}$ Prof Biochemistry, Central Labe, King Saud University (KSU), Riyadh 12372, Kingdom Saudi Arabia (KSA); elansary@ksu.edu.sa

\begin{abstract}
:
Background: Exposure to chronic low levels of aflatoxin B1 (AFB1) contamination can lead to immune suppression and nutritional consequences that might greatly contributed in the increase of hepatocellular carcinoma (HCC). The toxicity of AFB1 is greatly vary between different population, affected by age, gender, and environmental factors. Material and subjects: Aflatoxin B1 (AFB1) was measured in 50 blood samples collected from non B, C hepatitis viruses and non $\mathrm{CMV}-\mathrm{Ab}$ liver disease patients from different general hospitals and polyclinic in KSA during period 01-2013 to 06-2014. All Patients demonstrate elevation of ALT and AST with unknown etiology. Serum samples were obtained and kept at $-20{ }^{\circ} \mathrm{C}$ for AFB1detection. Results: Out of the 50 blood samples, 38 demonstrate a detectable serum level of AFB1 while the remaining 12 patients were AFB1 negative and used as control participants. While AST was non-significantly different in AFB1 exposed patients, ALT was significantly higher in AFB1 positive samples compared to control AFB1-negative. AFB1 was positively correlated with AST and ALT as liver function enzymes and with age as a risk factor of long duration of AFB1 chronic exposure. Multiple linear regression analysis ascertained the association between AFB1 chronic exposure and ALT increase in liver dysfunction Saudi patients. Conclusion: Measurement of elevated ALT as marker of liver injury in AFB1 chronically exposed Saudi patients can help to avoid the future development of HCC. Moreover, early detection of AFB1 exposure, together with early vaccination against $\mathrm{HBV}$ and $\mathrm{HCV}$ can remove the synergistic effects of these two etiological factors and thus decrease the risk of developing liver cancer.
\end{abstract}

\section{Keywords:}

aflatoxin B1; transaminases; hepatocellular carcinoma; Saudi patients; liver dysfunction 


\section{Introduction}

Aflatoxins is a very potent hepatotoxic and carcinogenic mycotoxin which is frequently reported as a food contaminant. AFB1 are probably the best known toxic metabolites produced by certain fungi usually developed on food due to bad storage conditions. AFB1 chronic exposure demonstrate genotoxic, mutagenic, immunosuppressive, and remarkable increase of hepatocellular carcinoma (HCC) $(1,2)$. Based on the fact that AFB1 recorded the most potent carcinogenic effects in both humans and animals, they have received greater attention compared to other mycotoxins. As it is realized that absolute safety is very difficult to be achieved, many developing countries among which is Saudi Arabia have attempted to decrease the toxicity of aflatoxins by regulations that control exposure that restrict the limits of these toxins in food and animal feed.

As aflatoxins are excreted in cow's milk, the exposure to these toxins has received a great health importance. It is well known that aflatoxin M1, as a metabolite of aflatoxin B1, is found in the milk of dairy cattle that have ingested feed contaminated with the AFB1. Hence, milk and dairy products can be targeted to decrease the exposure to AFB1 toxicity $(3,4)$.

Moreover AFB1 contamination demonstrates synergistic interaction with hepatitis B virus infection which usually lead to the development of human hepatocellular carcinoma (5). The human co-exposure to both AFB1 and hepatitis B was found to enhance early pre-neoplastic lesions in rat liver (6). Up to this information, the risk of developing HCC was found to be 30 times higher in hepatitis B and C virus chronic infection $(4,7)$. Understanding the mechanism through which HCC is related to AFB1 exposure can help to control the development of liver cancer (9).

This information initiate our interest to study the relationship between AFB1 chronic exposure, elevation of transaminases as measure of liver injury and age as risk factors to develop HCC in non B, C hepatitis viruses and non CMV-Ab Saudi patients. This might help to decrease the development of HCC in AFB1 -exposed individuals through early vaccination against HBV and $\mathrm{HCV}$ as synergistic risk factors in case of AFB1 chronic exposure.

\section{Material and methods:}

\section{Samples collection}

50 Blood samples were collected from liver disease patients have elevation in ALT and AST with unknown etiology; non B, C hepatitis viruses and non-cytomegalovirus- antibody (CMV$\mathrm{Ab}$ ) from different general hospitals and polyclinic in KSA during period 01-2013 to 06-2014. Serum samples were prepared from the blood and kept at $-20{ }^{\circ} \mathrm{C}$ for aflatoxin detection.

\section{Laboratory investigations}

The patients non B, C hepatitis viruses and non- $\mathrm{CMV}-\mathrm{Ab}$ and have elevation in liver profiles; were investigated with unHBsAg was carried by hemagglutination assay (Murex Diagnostics Limited, Dartford, UK) with radioimmunoassay testing of negative samples (Sorin Biomedica Diagnostics, Vercelli, Italy). anti-HCV and CMV-Ab were determined by third-generation enzyme-linked immunosorbent assay (ELISA; ORTHO Clinical Diagnostics, Neckargemund, Germany). Liver profiles ALT and AST detected by Kinetic biochemical testing (Promega, USA).

\section{Detection of aflatoxin concentration}

Aflatoxins were extracted from serum samples by using the methods of Wray and Hayes [10]. Where identification and quantification aflatoxins B1 by using HPLC (Beckman Model 110A) 
method of Tchana et al (11). The HPLC column used was an ODS-Sil-X-10 $\mu$ m reverse phase column $(4 \times 250 \mathrm{~mm}$, Perkin Elmer). Serum samples were injected $(25 \mu \mathrm{L})$ through a Perisorb RP $18,10-40 \mu \mathrm{m}$ pre-column $(4.9 \times 50 \mathrm{~mm}$, Waters $)$ at 2,000 psi pressure. The mobile phase used was bi-distilled water-acetonitrile-methanol $(16: 5: 5 \mathrm{v} / \mathrm{v} / \mathrm{v})$, at a rate of $1 \mathrm{~mL} . \mathrm{min}^{-1}$. Aflatoxin was detected using a Beckman fluorescent detector (Type 157) set at excitation wavelength of 365 $\mathrm{nm}$ and at emission $430 \mathrm{~nm}$.

\section{Confirmed ELISA assay of aflatoxin B1}

The presence of AFB1 in serum samples were confirmed by using an immuno- enzymatic commercial kit based on monoclonal antibodies specific for it (Transia, Lyon France). The extract was evaporated to dryness and taken up in the sample buffer provided in the kit, then $50 \mu \mathrm{L}$ of the serum sample was pipetted into duplicate wells of an ELISA plate which sensitised with the monoclonal antibody specific for aflatoxin AFB1. After incubation and washing $50 \mu \mathrm{L}$ of the specific monoclonal antibody conjugated to horseradish peroxidase dissolved in the conjugate buffer provided in the kit was added. Incubation followed by washing was done before the addition of the substrate. The intensity of the developed color was read using ELISA reader.

\section{Statistical analysis}

The data were analyzed using the Statistical Package for the Social Sciences (SPSS, Chicago, IL, USA). The results were expressed as mean \pm standard deviation of the mean (SD). All statistical comparisons between the 50 blood samples from liver disease individuals (elevation in ALT and AST with unknown etiology, $\mathrm{N}=12$ (negative for AFB1, used as control); non $\mathrm{B}, \mathrm{C}$ hepatitis viruses and non-cytomegalovirus- antibody, CMV-Abs, and AFB1 positive individuals and used as patients; $\mathrm{N}=38$ ) were performed using the one-way analysis of variance (ANOVA) Pearson's correlations were performed between the measured parameters. A $p$ value less than 0.05 was statistically considered significant

\section{Results}

Table 1 demonstrates levels of AST, ALT and AFB1 in sera of 50 liver disease patients with unknown etiology (i.e non B, C hepatitis viruses and non CMV-Ab). Out of the 50 samples, $38 / 50$ had a detectable serum level of AFB1 with concentrations varies from $0.5-1.675 \mu \mathrm{g} / \mathrm{L}$ and $12 / 50$ were negative and used as control participants. While AST was non-significantly different in AFB1 exposed patients, ALT was significantly higher in AFB1 positive samples compared to control AFB1-negative. Figure 1 demonstrates the percentage change in AST and ALT in AFB1 positive compared to control. Tables 2 and 3 demonstrate the correlation between AFB1 exposure and AST, ALT and age. It can be easily noticed that AFB1 was positively correlated with AST and ALT as liver function enzymes and with age as a risk factor of long duration of AFB1 exposure. Table 4 shows multiple linear regression analysis using ALT as dependent variable and AFB1 and age as independent variables or predictors. $R^{2}$ value of 0.461 shows that $46.1 \%$ of the change in ALT is associated or related to the elevated AFB1.

Table 1:

\begin{tabular}{|c|c|c|c|c|c|c|}
\hline Parameter & Group & $\mathrm{N}$ & Min. & Max. & Mean \pm S.D. & P value \\
\hline \multirow{2}{*}{ ALT $(\mu / \mathrm{L})$} & Control & 12 & 56.05 & 67.74 & $59.65 \pm 3.39$ & \\
\cline { 2 - 6 } & Patients & 38 & 56.45 & 115.30 & $68.10 \pm 14.69$ & \\
\hline
\end{tabular}




\begin{tabular}{|c|l|c|c|c|c|c|}
\hline \multirow{2}{*}{ Parameter } & \multicolumn{1}{|c|}{ Group } & $\mathrm{N}$ & Min. & Max. & Mean \pm S.D. & P value \\
\hline \multirow{2}{*}{ AST $(\mu / \mathrm{L})$} & Control & 12 & 35.23 & 62.01 & $43.32 \pm 7.01$ & \\
\cline { 2 - 7 } & Patients & 38 & 35.25 & 72.32 & $45.65 \pm 8.76$ & \\
\hline
\end{tabular}

- Table 1 describes the independent T-Test between Control and Patients groups in all ALT $(\mu / \mathrm{L})$ and AST $(\mu / \mathrm{L})$.

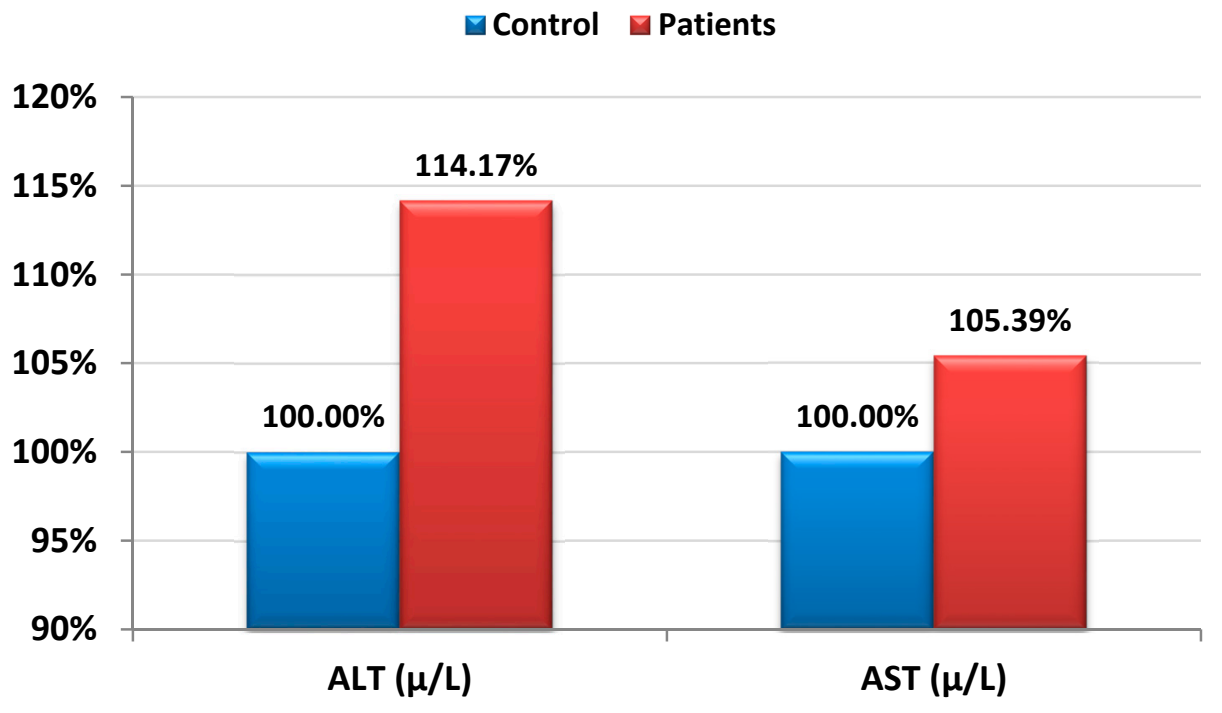

Fig. 1: Percentage change of ALT $(\mu / \mathrm{L})$ and AST $(\mu / \mathrm{L})$ in patients group compared to control group.

Table 2: Correlations between AFB1, AST, and ALT

\begin{tabular}{|l|c|c|c|}
\hline \multicolumn{1}{|c|}{ Parameters } & $\begin{array}{c}\text { R (Person } \\
\text { Correlation) }\end{array}$ & Sig. & \\
\hline AFB1 $(\mu \mathrm{g} / \mathrm{L}-1) \sim \operatorname{ALT}(\mu / \mathrm{L})$ & $0.687^{* *}$ & 0.001 & $\mathrm{~Pa}$ \\
\hline AFB1 $(\mu \mathrm{g} / \mathrm{L}-1) \sim \operatorname{AST}(\mu / \mathrm{L})$ & $0.503^{* *}$ & 0.001 & $\mathrm{~Pa}$ \\
\hline
\end{tabular}

${ }^{* *}$ Correlation is significant at the 0.01 level.

a Positive correlation. 


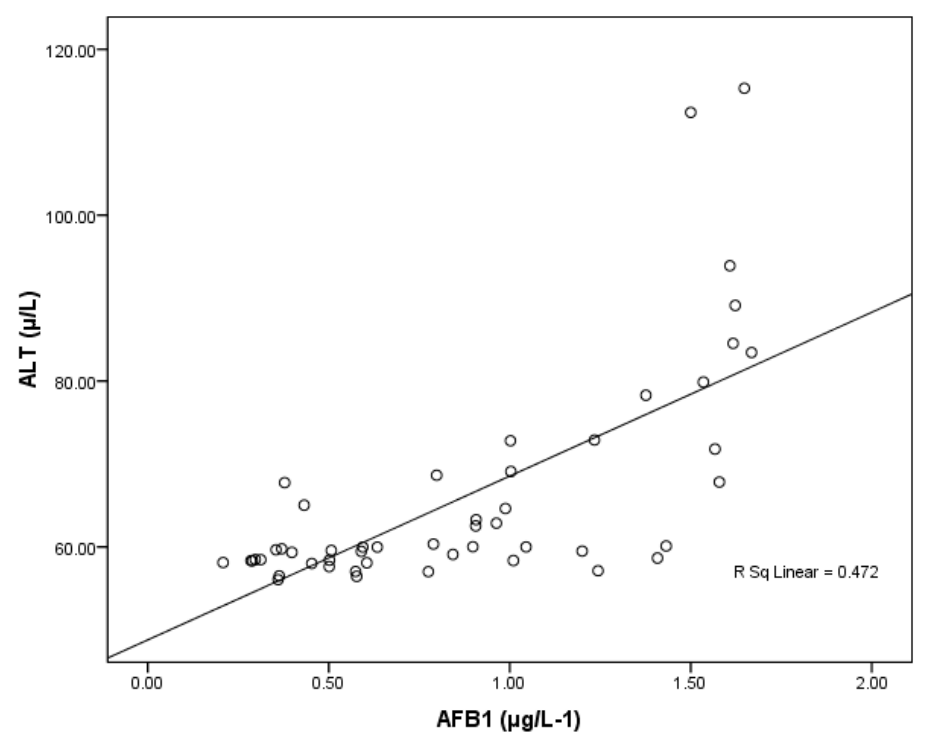

Fig. 2: Correlation between AFB1 ( $\mu \mathrm{g} / \mathrm{L}-1)$ and ALT $(\mu / \mathrm{L})$ with best fit line curve (positive correlation).

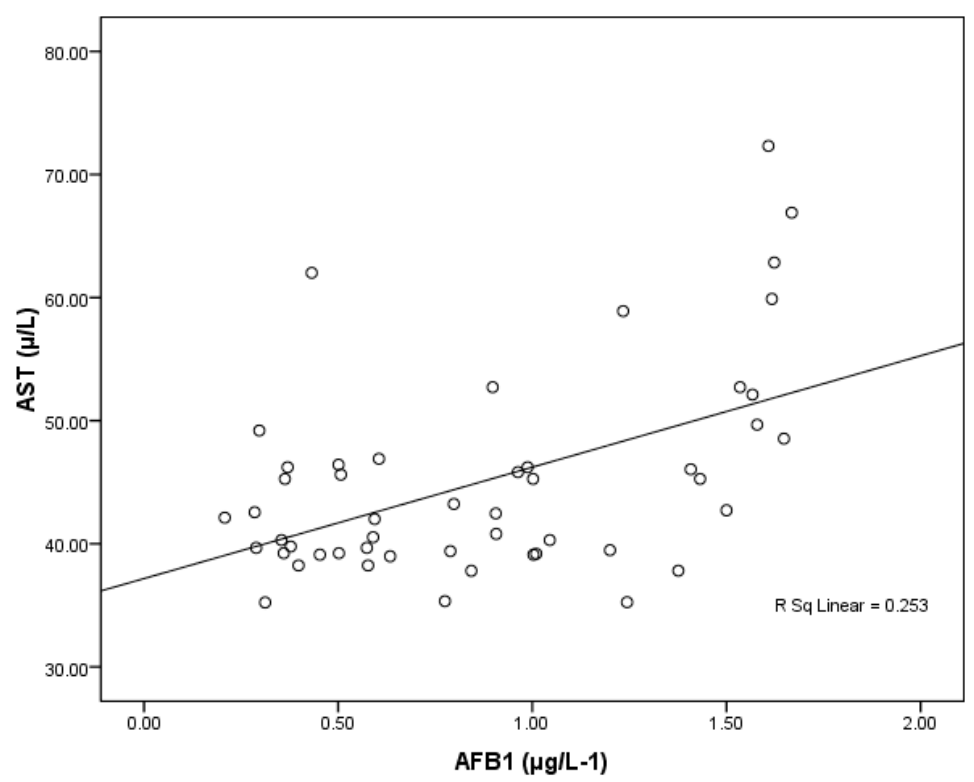

Fig. 3: Correlation between AFB1 ( $\mu \mathrm{g} / \mathrm{L}-1)$ and AST $(\mu / \mathrm{L})$ with best fit line curve (positive correlation).

Table 3: Correlation between AFB1 and age

\begin{tabular}{|l|c|c|c|}
\hline \multicolumn{1}{|c|}{ Parameters } & $\begin{array}{c}\text { R (Person } \\
\text { Correlation) }\end{array}$ & Sig. & \\
\hline AFB1 $(\mu \mathrm{g} / \mathrm{L}-1) \sim$ Age & $0.619^{* *}$ & 0.001 & $\mathrm{~Pa}$ \\
\hline
\end{tabular}

${ }^{* *}$ Correlation is significant at the 0.01 level.

a Positive correlation. 


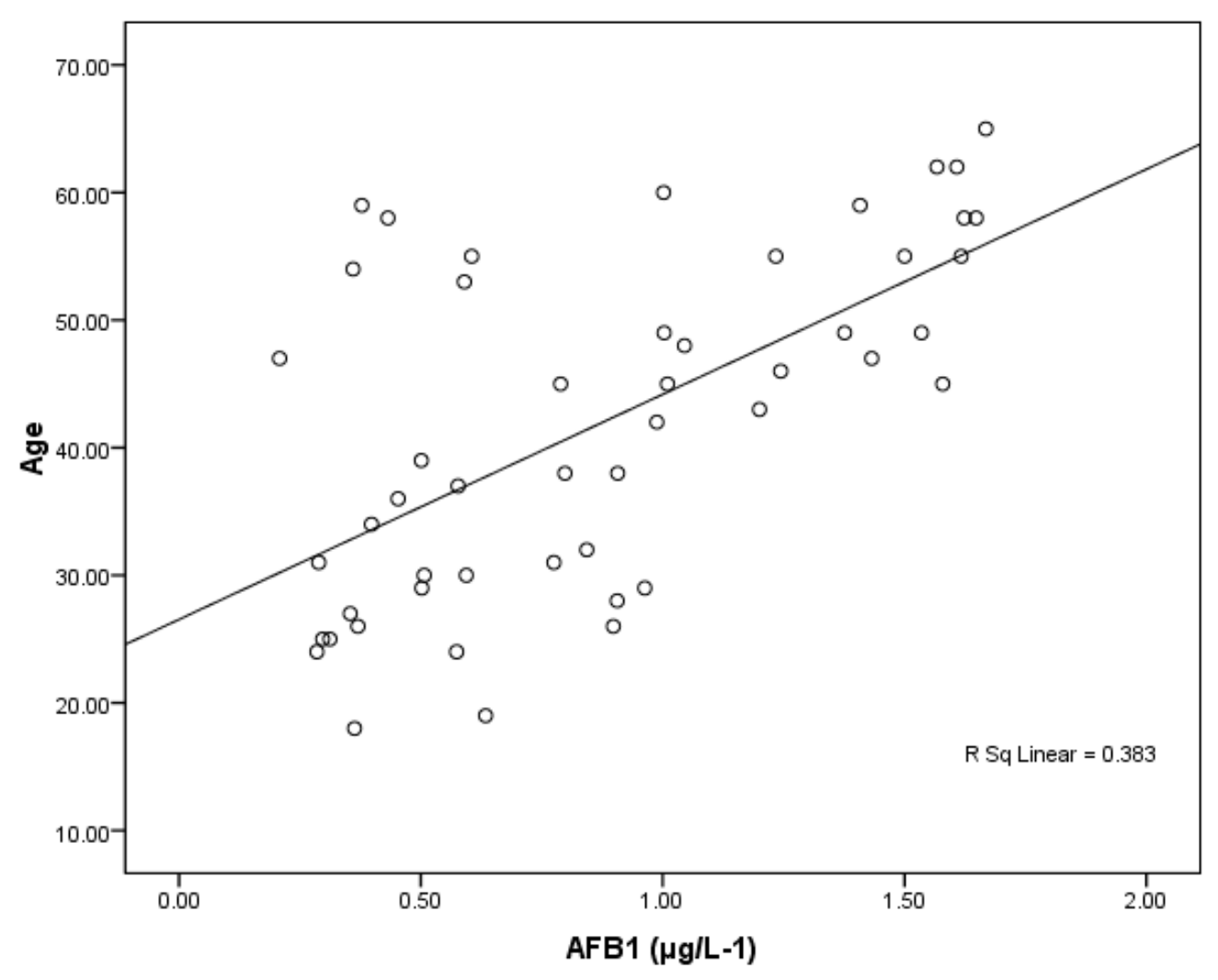

Fig. 1: Correlation between AFB1 ( $\mu \mathrm{g} / \mathrm{L}-1)$ and Age with best fit line curve (positive correlation).

Table 4: Multiple regression using stepwise method for ALT as a dependent variable

\begin{tabular}{|l|c|c|c|c|c|}
\hline \multirow{2}{*}{ Predictor Variable } & & Beta & P value & \multirow{2}{*}{$\begin{array}{c}\text { Adjusted } \mathrm{R} \\
\text { square }\end{array}$} & \multicolumn{2}{|c|}{ Model } \\
\cline { 5 - 6 } & & & F value & P value \\
\hline AFB1 & 0.024 & 0.001 & 0.461 & 42.879 & 0.001 \\
\hline
\end{tabular}

\section{Discussion}

Aflatoxins is considered the most agent naturally causing hepatocarcinogens; and the impact of aflatoxin on public health is detected in both acute and chronic exposure $(10,27)$. Acute exposure of aflatoxin (aflatoxicosis) can result fulminant liver failure $(11,28)$; and chronic exposure of aflatoxin has been linked to development of HCC $(12,27)$. In this research include difficulties in detection clinical outcomes in some resource-constrained environments and difficulty in accurately detecting aflatoxin exposure.

Data presented in table 1 demonstrate that AFB1 exposed patients has a significantly higher ALT enzyme compared to control. As ALT is a biomarker of liver dysfunction, this observation can help to suggest that a high level of the hepatotoxic AFB1 was involved in the developed liver injury. This is in good agreement with the previous reports of Barton et al. (12) which recorded that interperitonial injection of AFB1 to rats demonstrated a dose-dependent hepatotoxicity measured as marked elevations in serum ALT and AST activities concomitant with histologic changes. As ALT exceeds AST in toxic hepatitis, viral hepatitis, and cholestatic hepatitis, the higher concentration of ALT compared to AST presented in Table 1, in AFB1 
negative (control) and AFB1 positive (patients) ascertained that all investigated samples demonstrate liver injury (13). This in turn can confirm the hepato-toxic effect of AFB1 as much higher increase in ALT compared to AFB1 negative participants. Use of ALT as predictive marker of AFB1 liver toxicity can find support in the recent work of Yang et al. (14) in which the elevated level of serum ALT was one of the cascade three steps model of liver injury induced by total saponins of plant origin. On the other hand, the non-significant elevation of AST in response to AFB1 toxicity, reported in the present study, is not in good agreement with the previous study of Allameh et al. (15) which showed that serum lactate dehydrogenase (LDH) and AST demonstrate more dependency on the exposure duration and concentration of aflatoxins.

Tables 2 together with figures 2 and 3 demonstrate Pearson's correlations between ALT, AST, age and AFB1 as the four measured variables in this study It can be easily noticed that AFB1was positively correlated $(\mathrm{P}<0.001)$ with AST and ALT. This can suggest the importance of both enzymes as markers of AFB1 hepatotoxicity. The positive correlation between AFB1 and age (Table 3 and figure 4) in AFB1 positive samples can prove that detection limit of AFB1 fall within certain limits which need longer period to be reached (i.e older participants). This suggestion can find support in the recent work of Rieswijk et al. (16) which proves for the first time that AFB1 induced an epigenetic persistent toxic effect eventually leads to HCC. They were able to identify methyl DNA-mRNA-interactions as marker for a persistent epigenetic effect associated with the early onset of AFB1-induced HCC.

The general purpose of multiple regressions is to learn more about the relationship between several independent or predictor variables (AFB1 and age) in the present study, and a dependent or criterion variable, ALT through the recorded $\mathrm{R}^{2}$ and $\mathrm{B}$ coefficient values. In this analysis $\mathrm{R}^{2}$ describes the proportion or percentage of variance in the dependent variable explained by the variance in the independent variables together which sometimes called the predictor variables.

Table 4 demonstrates the contribution of AFB1 as predictor variable in the elevation of ALT as dependent variable. This suggestion can find support in the previous study of Wild et al. (17) which proved that increased liver injury may modulate AFB1 metabolism. The relationship of ALT elevation and AFB1 and vice versa can also be supported through considering the early work of Thaxton and Hamilton (18) and Gawai et al. (19) in which the proved the elevation of ALT, as indication of acute liver injury, in birds that had been given a single dose of aflatoxin compared to control untreated birds.

The reported increase of ALT in AFB1 positive patients can also find support in more recent studies which demonstrate the significant increase of ALT among other biochemical parameters in rats fed AFB1 (20-22). Therefore this study exhibits similarity to the previously research which prove that AFB1-induced liver injury can be attributed to the oxidative stress. Based on this similarity regarding the elevation of ALT in Saudi patients with liver dysfunction, as subject of the present study, curcumin and green tea as two supplements show ameliorative effects of AFB1-induced liver energy can be used to avoid the carcinogenic effect of AFB1 as long as possible in Saudi populations who demonstrate AFB1 positivity together with elevated ALT. In addition to these recommended supplementations, a reasonable and promising clinical intervention to reduce aflatoxin-related HCC is early vaccination against HBV and HCV. This can be supported through the scientific fact that early vaccination of children against HBV has, over the past 30 years, significantly decreased HBV infection in several regions, including Europe (23,24), Taiwan (25) and Thailand (26). This might help to control the carcinogenic effect of aflatoxin, because removing the synergistic impact between $\mathrm{HBV}$ and aflatoxin exposure would remarkably reduce HCC risk $(27,28)$.

\section{Acknowledgements}


The authors would like to thank King Abdul Aziz City for Science and Technology (KACST) for supporting the present work as part of NTPC funded projects No. AT-34-208. Our gratitude is also extended to Princess Nora University (PNU) and King Saud University for provided the infrastructure and facilities required for performing this work successfully.

\section{Author Contributions}

Randa M. Farag contributed to the planning and experimental working of the study and wrote the paper with Afaf El- Ansary interpreted the data and Statics analysis. Khalid A Alsaleh and Dujana AlAyobi were responsible for obtaining Institutional Review Board (IRP) approval to perform the study was obtained from the College of Medicine, King Saud University, Riyadh, Kingdom of Saudi Arabia; Research project No.E-14-1116. Informed consent was obtained from all cases to the collection of specimens. Hye-Joo Kwon and Ehab A Serour spell shacking and reviewer. All authors evaluated and revised the manuscript.

\section{Conflicts of Interest}

The author declare no conflict of interest.

\section{References:}

1. Abbès, S.; Ben Salah-Abbès, J.; Abdel-Wahhab, M.A.; Ouslati, R. Immunotoxicological and biochemical effects of aflatoxins in rats prevented by Tunisian montmorillonite with reference to HSCAS. Immunopharmacol. Immunotoxicol. 2010, 32, 514-522.

2. Abdel-Wahhab, M.A.; Aljawish, A.; El-Nekeety, A.A.; Abdel-Aiezm, S.H.; Abdel-Kader, H.A.M.; Rihn, B.H.; Joubert, O. Chitosan nanoparticles and quercetin modulate gene expression and prevent the genotoxicity of aflatoxin B1 in rat liver. Toxicol. Rep. 2015, 2, 737-747.

3. WHO. The global burden of disease: 2004 update. Available online: http://www.who.int/healthinfo/global_burden_disease/2004_report_update/en/index.html (accessed 17 November 2016).

4. Wild, C.P.; Gong, Y.Y. Mycotoxins and human disease: a largely ignored global health issue. Carcinogenesis 2010, 31, 71-82.

5. Wild, C.P.; Miller, J.D.; Groopman, J.D., Eds.; Mycotoxin control in low- and middle-income countries; IARC: Lyon, France, 2015; Available online: https://www.iarc.fr/en/publications/pdfsonline/wrk/wrk9/IARC publicationWGR9 full.pdf (accessed 17 November 2016).

6. Carlson, D.B.; Williams, D.E.; Spitsbergen, J.M.; Ross, P.F.; Bacon, C.W.; Meredith, F.I.; Riley, R.T. Fumonisin B1 promotes aflatoxin B1 and N-methyl-N'-nitronitrosoguanidine-in rainbow trout. Toxicol. Appl. Pharmacol. 2001, 172, 29-36.

7. Kirk, G.D.; Bah, E.; Montesano, R. Molecular epidemiology of human liver cancer: insights into etiology, pathogenesis and prevention from The Gambia, West Africa. Carcinogenesis 2006, 27, 2070-2082.

8. Kuang S.-Y.; Lekawanvijit, S.; Maneekarn, N.; Thongsawat, S.; Brodovicz, K.; Nelson, K.; Groopman, J.D. Hepatitis B 1762T/1764A mutations, hepatitis C infection, and codon 249 p53 mutations in hepatocellular carcinomas from Thailand. Cancer. Epidemiol. Biomarkers Prev. 2005, 14, 380-384.

9. Wild, C.P.; Montesano, R. A model of interaction: aflatoxins and hepatitis viruses in liver cancer aetiology and prevention. Cancer Lett. 2009, 286, 22-28.

10. Wray, B.B.; Hayes, A.W. Aflatoxin B1 in the serum of a patient with primary hepatic carcinoma. Environ. Res. 1980, 22, 400-403.

11. Tchana, A.N.; Moundipa, P.F.; Tchouanguep, F.M. Aflatoxin contamination in food and body fluids in relation to malnutrition and cancer status in Cameroon. Int. J. Environ. Res. Public Health. 2010, 7, 178-188.

12. Barton, C.C.; Hill, D.A.; Yee, S.B.; Barton, E.X.; Ganey, P.E.; Roth, R.A. Bacterial lipopolysaccharide exposure augments aflatoxin B(1)-induced liver injury. Toxicol. Sci. 2000, 55, 444-452.

13. Rosalki, S.B.; Mcintyre, N. Biochemical investigations in the management of liver disease. 2nd ed.; Oxford university press: New York, 1999; pp. 503-521.

14. Yang, F.; Liang, Y.; Xu, L.; Ji, L.; Yao, N.; Liu, R.; Shi, L.; Liang, T. Exploration in the cascade working mechanisms of liver injury induced by total saponins extracted from Rhizoma Dioscorea bulbifera. Biomed. Pharmacother. 2016, 83, 1048-1056. 
15. Allameh, A.; Safamehr, A.; Mirhadi, S.A.; Shivazad, M.; Razzaghi-Abyaneh, M.; Afshar-Naderi, A. Evaluation of biochemical and production parameters of broiler chicks fed ammonia treated aflatoxin contaminated maize grains. Anim. Feed Sci. Technol. 2005, 122, 289-301

16. Rieswijk, L.; Claessen, S.M.; Bekers, O.; van Herwijnen, M.; Theunissen, D.H.; Jennen, D.G.; de Kok, T.M.; Kleinjans, J.C.; van Breda, S.G. Aflatoxin B1 induces persistent epigenomic effects in primary human hepatocytes associated with hepatocellular carcinoma. Toxicology. 2016, 350-352, 31-39.

17. Wild, C.P.; Fortuin, M.; Donato, F.; Whittle, H.C.; Hall, A.J.; Wolf, C.R.; Montesano, R. Aflatoxin, liver enzymes, and hepatitis B virus infection in Gambian children. Cancer Epidemiol. Biomarkers Prev. 1993, 2, 555-561.

18. Thaxton, V.P.; Hamilton, P.B. Studies on immunosuppression in chicken by aflatoxin. Poultry Sci. 1971, 53, 724-725.

19. Gawai, K.R.; Vodela, J.K.; Dalvi, P.S.; Dalvi, R.R. Comparative assessment of the effect of aflatoxin $\mathrm{B} 1$ on hepatic dysfunction in some mammalian and avian species. Comp. Biochem. Physiol. 1992, 101, 415-418.

20. Mathuria, N.; Verma, R.J. Ameliorative effect of curcumin on aflatoxin-induced toxicity in serum of mice. Acta. Pol. Pharm. 2008, 65, 339-343.

21. Alm-Eldeen, A.A.; Mona, M.H.; Shati, A.A.; El-Mekkawy, H.I. Synergistic effect of black tea and curcumin in improving the hepatotoxicity induced by aflatoxin B1 in rats. Toxicol. Ind. Health 2013, 31, 1269-1280.

22. Karabacak, M., Eraslan, G., Kanbur, M., Sarıca, Z.S. Effects of Tarantula cubensis D6 on aflatoxin-induced injury in biochemical parameters in rats. Homeopathy 2015, 104, 205-210.

23. Bonanni, P.; Pesavento, G.; Bechini, A.; Tiscione, E; Mannelli, F.; Benucci, C.; Nostro, A.L. Impact of universal vaccination programmes on the epidemiology of hepatitis B: 10 years of experience in Italy. Vaccine 2003, 21, 685-691.

24. Williams, J.; Nokes, D.J.; Medley, G.F.; Anderson, R.M. The transmission dynamics of hepatitis B in the UK: a mathematical model for evaluating costs and effectiveness of immunization programmes. Epidemiol. Infect. 1996, 116, 71-89.

25. Chen, H.; Chang, M.H.; Ni, Y.H.; Hsu, H.Y.; Lee, P.I.; Lee, C.Y.; Chen, D.S. Seroepidemiology of hepatitis $\mathrm{B}$ virus infection in children: ten years of mass vaccination in Taiwan. JAMA 1996, 276, 906-908.

26. Jutavijittum, P.; Jiviriyawat, Y; Yousukh, A.; Hayashi, S.; Toriyama, K. Evaluation of a hepatitis B vaccination program in Chiang Mai, Thailand. Southeast Asian J. Trop. Med. Public Health 2005, 36, 207-212.

27. IARC (International Agency for Research on Cancer) 1993. Aflatoxins. IARC Monogr Eval Carcinog Risks Hum 56:245-395.

28. Lewis, L.; Onsongo, M.; Njapau, H.; Schurz-Rogers, H.; Luber, G.; Kieszak S, et al. 2005. Aflatoxin contamination of commercial maize products during an outbreak of acute aflatoxicosis in eastern and central Kenya. Environ Health Perspect 113:1763-1767.

(C) 2016 by the authors; licensee Preprints, Basel, Switzerland. This article is an open access article distributed under the terms and conditions of the Creative Commons by Attribution (CC-BY) license (http://creativecommons.org/licenses/by/4.0/). 